\title{
Diaphragmatic Stripping
}

National Cancer Institute

\section{Source}

National Cancer Institute. Diaphragmatic Stripping. NCI Thesaurus. Code C132070.

A surgical procedure that refers to the removal of the diaphragmatic sites affected by cancer. 